\title{
Development of Value Added Products by Incorporating Healthy Heart Mixture for the Management of Cardiovascular Diseases
}

\author{
Ishani Rathore ${ }^{1}$, Gargi Saxena ${ }^{2}$ \\ ${ }^{1,2}$ Department of Home Science, The IIS University, Gurukul marg, SFS, Mansarovar, Jaipur, India
}

\begin{abstract}
Cardiovascular disease (CVDs) have a major share in the prevalence of non communicable disease which is showing a rise among Indian population and is further increasing among younger age group. According to WHO, the prevalence of CVD shall double in India in both men and women from 7.7 and 5.5 million respectively from the year 2000 till 2020. The contributing factor for rise of CVDs incidence are socioeconomic determinants, modifiable and non modifiable risk factors, increase in intermediate risk factor. Intake of Dietary fiber is found to be associated with decreased risk of CVD due to the LDL Cholesterol lowering capacity. The study was carried with an objective to prepare Healthy Heart Mixture constituting of oats, flaxseed and isabgol in proportion of 20\%, $10 \%$ and $10 \%$ respectively and develop value added products by incorporating it in varied proportions in selected standardized recipes khakhra, thepla, baked mathri and baked namkeen in proportion ranging from 10\% - 50\% which were evaluated for sensory characteristics by 5 panel member selected through sensitivity threshold test. The mean overall acceptability scores was found to be highest for product with code 552,662,772 and 882 ranging from 4.32-3.16 (khakhra), 4.4-3.64 (thepla), 4.66-3.32 (baked mathri) and 4.74-3.04 (baked namkeen) on a five point rating scale followed by cost calculation according to latest market list ranging from Rs 3.70-18.80 (khakhra), 5.17-20.32 (thepla), 3.36-16.96 (baked mathri) and 14.31-23.56 (baked namkeen). For nutritional analysis, oven dried healthy heart mixture was used for estimation.
\end{abstract}

Keywords: Cardiovascular disease, fiber, health benefits, cholesterol lowering, oats, flaxseeds, isabgol

\section{Introduction}

The major cause of disability and premature death throughout the world is cardiovascular disease for which atherosclerosis being the underlying pathology which develops over many years. The clinical events and premature death in people with established CVD as well as in those with the one at high CVD risk can be reduced by risk factor modification (WHO, 2007).

In India, the estimated mortality from coronary heart disease was 1.6 million in the year 2000 as reported by Global Burden of Disease (GBD) (Shah et al., 2010). Physical inactivity, smoking, hyperlipidemia, obesity, diabetes, familial history and poor health are the major risk factor for developing CVD among which many are modifiable (Coleman et al., 2013).

Studies have shown that intake of dietary fiber is associated with decreased risk of cardiovascular risk including ischemic heart disease, stroke and also a lower risk of diabetes (Coleman et al., 2013). The enzymatic activity of cholesterol-7- $\alpha$-hydroxylase, the major regulatory enzyme in hepatic conversion of cholesterol to bile acids in increased by dietary fiber which contributes to hepatic cholesterol depletion (Arranz et al., 2012). The effect on total cholesterol have a varied range from $18 \%$ to $0 \%$ in trials of oats products, $17 \%$ to $3 \%$ for psyllium, from $16 \%$ to $5 \%$ for pectin and from $17 \%$ to $4 \%$ for guar gum (Brown et al., 2016). Many bioactive substances present in food that are rich in fiber have a clear role in prevention of cardiovascular disease (Arranz et al., 2012). Flaxseed constituent can have a positive effect on blood lipid levels, blood pressure, endothelial function and inflammation to alleviate CVD risk (Adolphe et al., 2015).There are three main components of flaxseeds which are associated with improved cardiovascular health: the omega-3 polyunsaturated fatty acid alphalinolenic acid (20\% of dry weight); plant lignan secoisolariciresinol diglucoside ( $1 \%$ by dry weight) and soluble fiber ( $6 \%$ of dry weight). Dietary fiber from flaxseeds have cholesterol lowering effect as cholesterol is surrounded by the gel formation because of soluble fiber content of flaxseed which inhibits cholesterol absorption and leads to more excretion of cholesterol (Bernacchia et al., 2014). Oats as part of diet low in saturated fat and cholesterol may reduce the heart disease risk. Beta glucan in oats is active cholesterol reducing component which binds bile acid and increases their fecal excretion also bacterial fermentation of beta glucan increases the release of short fatty chain fatty acids which inhibit cholesterol biosynthesis (Katz et al., 2001). The mechanism for isabgol mediated cholesterol reduction involves bile acid cycle, increased bile acid secretion helps in decrease fat absorption and also reduce circulating bile acid amount which increases bile acid secretion in liver utilizing cholesterol precursors and also decrease the absorption of cholesterol (Narayan et al., 2005).

\section{Materials and Methods}

Sample selection and preparation of Healthy Heart Mixture. For the present investigation flaxseeds, oats and isabgol were purchased from the local market of the Jaipur city in a single lot to avoid varietal differences. The ingredients were initially observed for physical contamination like stones and other foreign matter. A mixture constituting of oats, flaxseed and isabgol was worked out in various proportion among which the most acceptable proportion was of oats $20 \%$, flaxseed $10 \%$, and isabgol $10 \%$. These ingredients were grinded together in measured amount. 


\section{International Journal of Science and Research (IJSR) ISSN (Online): 2319-7064 \\ Index Copernicus Value (2013): 6.14 | Impact Factor (2015): 6.391}

Table 1: Proportion of Healthy Heart Mixture

\begin{tabular}{|c|c|}
\hline Ingredient & Amount $(\mathrm{g})$ \\
\hline Oats & $50 \mathrm{~g}$ \\
\hline Flaxseed & $25 \mathrm{~g}$ \\
\hline Isabgol & $25 \mathrm{~g}$ \\
\hline Total & $100 \mathrm{~g}$ \\
\hline
\end{tabular}

Preparation of recipes comprising of Healthy Heart Mixture Firstly standardization of selected recipes, Khakhra, thepla, baked mathri and baked namkeen was done after which variations of these selected recipes were developed by substituting healthy heart mixture with the basic ingredients of the recipe in various proportion ranging from $10 \%-50 \%$. The basic ingredient, whole wheat flour was substituted with healthy heart mixture in khakhra, thepla and baked mathri and in case of baked namkeen with bengal gram flour in various proportions of $10 \%, 20 \%, 30 \%, 40 \%, 50 \%$.

Table 2: Different proportions of Healthy Heart Mixture added to the basic recipe

\begin{tabular}{|c|c|c|}
\hline $\begin{array}{c}\text { Recipe code } \\
\text { (khakhra, thepla, } \\
\text { baked mathri } \text { and } \\
\text { baked namkeen) }\end{array}$ & $\begin{array}{c}\text { Amount of basic } \\
\text { ingredient(Whole } \\
\text { wheat flour/ Bengal } \\
\text { gram flour) }\end{array}$ & $\begin{array}{c}\text { Amount of } \\
\text { Healthy } \\
\text { Heart } \\
\text { Mixture }\end{array}$ \\
\hline $551,661,771,881$ & $100 \mathrm{~g}$ & Nil \\
\hline $552,662,772,882$ & $90 \mathrm{~g}$ & $10 \mathrm{~g}$ \\
\hline $553,663,773,883$ & $80 \mathrm{~g}$ & $20 \mathrm{~g}$ \\
\hline $554,664,774,884$ & $70 \mathrm{~g}$ & $30 \mathrm{~g}$ \\
\hline $555,665,775,885$ & $60 \mathrm{~g}$ & $40 \mathrm{~g}$ \\
\hline $556,666,776,886$ & $50 \mathrm{~g}$ & $50 \mathrm{~g}$ \\
\hline
\end{tabular}

Sensory evaluation and Cost analysis of prepared recipes

The sensory attributes such as appearance, color, taste, after taste and overall acceptability were assessed on a five point rating scale. Total four recipes were prepared, standardized and then evaluated by semi trained panel members selected through sensitivity threshold test. Cost of each recipe along with its variation was calculated according to the current market list.

\section{Stastical analysis}

Data collected for each recipe evaluated for sensory characteristics using five point rating scale was compiled by calculating the overall mean acceptability and standard deviation of each selected recipe. Data was analyzed using Microsoft Excel software version 2007.

\section{Results and Discussion}

In the present study healthy heart mixture was prepared comprising of oats, flaxseed and isabgol in the proportion of $20 \%, 10 \%$ and $10 \%$ respectively. The prepared healthy heart mixture was substituted with the basic ingredient of the standard recipes in varied proportion of $10 \%, 20 \%, 30 \%$, $40 \%$ and $50 \%$ respectively. For the recipe Khakhra, Thepla and Baked mathri, the basic ingredient wheat flour was substituted with the healthy heart mixture ranging from $10 \%$ - 50\% and in case of baked namkeen the healthy heart mixture was substituted with Bengal gram flour ranging from $10 \%-50 \%$.

Table 3: Mean sensory score of the standardized healthy heart mixture recipe obtained on a five point rating scale

\begin{tabular}{|c|c|c|c|c|c|c|}
\hline Code & Appearance & Color & Taste & After Taste & Overall Acceptability & Overall Mean Score \\
\hline 551 (control) & 5 & 5 & 5 & 5 & 5 & 5 \\
\hline 552 & $4.6 \pm 0.547$ & $4.4 \pm 0.547$ & $4.6 \pm 0.894$ & $4.6 \pm 0.836$ & $4.6 \pm 1.095$ & $4.32 \pm 0.109$ \\
\hline 553 & $4.4 \pm 0.547$ & $4.4 \pm 0.547$ & $4.1 \pm 0.547$ & $4.2 \pm 0.447$ & $4.2 \pm 0.447$ & $4.26 \pm 0.130$ \\
\hline 554 & $4.0 \pm 0.707$ & $4.0 \pm 0.707$ & $4.0 \pm 0.707$ & $4 \pm 0.707$ & $3.8 \pm 0.836$ & $3.96 \pm 0.089$ \\
\hline 555 & $3.6 \pm 0.894$ & $3.6 \pm 0.894$ & $3.4 \pm 0.547$ & $3.4 \pm 0.547$ & $3.4 \pm 0.894$ & $3.48 \pm 0.109$ \\
\hline 556 & $3.4 \pm 1.140$ & $3.4 \pm 1.140$ & $3 \pm 0.707$ & $3 \pm 0.707$ & $3.0 \pm 1.224$ & $3.16 \pm 0.219$ \\
\hline
\end{tabular}

Table 4: Mean sensory score of the standardized healthy heart mixture recipe obtained by five point hedonic ranking scale

\begin{tabular}{|c|c|c|c|c|c|c|}
\hline Code & Appearance & Color & Taste & After Taste & Overall Acceptability & Overall Mean Score \\
\hline 661 (control) & 5 & 5 & 5 & 5 & 5 & 5 \\
\hline 662 & $4.4 \pm 0.547$ & $4.4 \pm 0.547$ & $4.4 \pm 0.547$ & $4.4 \pm 0.547$ & $4.4 \pm 0.547$ & 4.4 \\
\hline 663 & $4.4 \pm 0.547$ & $4.4 \pm 0.547$ & $4.2 \pm 0.447$ & $4.2 \pm 0.447$ & $4.2 \pm 0.447$ & $4.28 \pm 0.109$ \\
\hline 664 & $4 \pm 0.707$ & $4 \pm 0.707$ & $3.8 \pm 0.836$ & $3.8 \pm 1.09$ & $4 \pm 0.707$ & $3.92 \pm 0.109$ \\
\hline 665 & $3.6 \pm 0.547$ & 4 & $3.6 \pm 0.547$ & $3.6 \pm 0.547$ & $3.6 \pm 0.547$ & $3.68 \pm 0.178$ \\
\hline 666 & $3.6 \pm 0.547$ & $3.8 \pm 0.447$ & $3.6 \pm 0.547$ & $3.6 \pm 0.547$ & $3.6 \pm 0.547$ & $3.64 \pm 0.089$ \\
\hline
\end{tabular}

Table 5: Mean sensory scores of the standardized healthy heart mixture baked mathri obtained by five point hedonic rating

\begin{tabular}{|l|l|l|l|l|l|l|}
\hline Code & Appearance & Color & Taste & After Taste & Overall Acceptability & Overall Mean Score \\
\hline 771 (control) & 5 & 5 & 5 & 5 & 5 & 5 \\
\hline 772 & $4.7 \pm 0.547$ & $4.8 \pm 0.447$ & $4.8 \pm 0.447$ & $4.4 \pm 0.547$ & $4.9 \pm 0.223$ & $4.66 \pm 0.181$ \\
\hline 773 & $4.6 \pm 0.44$ & $4.7 \pm 0.447$ & $4.7 \pm 0.44$ & $4.2 \pm 0.836$ & $4.7 \pm 0.670$ & $4.64 \pm 0.250$ \\
\hline 774 & $4 \pm 0.707$ & $4.1 \pm 0.547$ & $4.2 \pm 0.447$ & $3.7 \pm 0.447$ & $4 \pm 0.707$ & $4 \pm 0.187$ \\
\hline 775 & $3.8 \pm 0.707$ & $3.8 \pm 0.547$ & $3.6 \pm 0.894$ & $3.6 \pm 0.894$ & $3.6 \pm 0.894$ & $3.58 \pm 0.04$ \\
\hline 776 & $3.5 \pm 1.303$ & $3.6 \pm 1.303$ & $3 \pm 0.707$ & $3 \pm 0.707$ & $3 \pm 0.707$ & $3.32 \pm 0.438$ \\
\hline
\end{tabular}




\section{International Journal of Science and Research (IJSR) \\ ISSN (Online): 2319-7064 \\ Index Copernicus Value (2013): 6.14 | Impact Factor (2015): 6.391}

Table 6: Mean sensory scores of the standardized healthy heart mixture baked Namkeen obtained by five point rating scale

\begin{tabular}{|c|c|c|c|c|c|c|}
\hline Code & Appearance & Color & Taste & After Taste & Overall Acceptability & Overall Mean Score \\
\hline 881 (control) & 5 & 5 & 5 & 5 & 5 & 5 \\
\hline 882 & $4.8 \pm 0.447$ & $4.8 \pm 0.447$ & $4.8 \pm 0.447$ & $4.8 \pm 0.447$ & $4.8 \pm 0.447$ & $4.74 \pm 0.054$ \\
\hline 883 & $4.3 \pm 0.670$ & $4.1 \pm 0.547$ & $4.7 \pm 0.447$ & $4.7 \pm 0.447$ & $4.7 \pm 0.447$ & $4.56 \pm 0.336$ \\
\hline 884 & $3.9 \pm 0.223$ & $3.9 \pm 0.223$ & $3.8 \pm 0.447$ & $3.8 \pm 0.447$ & $3.8 \pm 0.447$ & $3.84 \pm 0.054$ \\
\hline 885 & $3 \pm 0.707$ & $3.2 \pm 0.447$ & $3.3 \pm 0.447$ & $3.3 \pm 0.447$ & $3.3 \pm 0.447$ & $3.22 \pm 0.130$ \\
\hline 886 & $3 \pm 0.707$ & $3.2 \pm 0.447$ & $3 \pm 0.707$ & $3 \pm 0.707$ & $3 \pm 0.707$ & $3.04 \pm 0.08$ \\
\hline
\end{tabular}

The prepared recipes were evaluated for the sensory attributes - appearance, color, taste, after taste and overall acceptability by the panel member selected through sensitivity threshold test. The value of mean scores obtained on a five point rating scale for different attributes like appearance, color, taste, after taste, overall acceptability for all the prepared recipe was calculated. In all the four recipes i.e khakhra, thepla, baked mathri and baked namkeen the highest mean score obtained was for recipes with code 552 , 662,772 and 882 was $4.32,4.4,4.66$ and 4.74 respectively having $10 \mathrm{~g}$ of healthy heart mixture indicating that the product was liked very much. The overall acceptability mean score for the variations of the four recipes ranges from $3.16-4.32,3.64-4.4,3.32-4.66$ and $3.04-4.74$ respectively.

In all the four recipes, with increasing amount of healthy heart mixture the sensory attributes decreased which may be contribute to the after taste of the isabgol. Also during the preparation of the recipes the amount of water required for making the dough increased with the increasing proportion of healthy heart mixture which was mainly due to the water absorbing capacity of the isabgol which affected the quality of the dough as with standard amount of water the prepared dough was hard which affected the sensory quality and it was hard to prepare with reduced binding capacity thereby decreasing the acceptability score of the product having $50 \mathrm{~g}$ of healthy heart mixture. It was also observed that with increase in amount of healthy heart mixture the color parameter was affected with increasing amount of flaxseed thereby decreasing its overall acceptability in case of product having $50 \mathrm{~g}$ of healthy heart mixture (Goyal et al., 2014) (Rathi et al., 2012).

The cost calculated for each selected recipe along with its variation were ranging as khakhra (Rs $3.70-18.80)$, thepla (Rs 5.17 - 20.32), baked mathri (Rs 3.05 - 18.20) and baked namkeen (Rs $9.41-22.21$ ) respectively and the cost of the most acceptable recipe with code 552, 662, 772 and 882 was Rs 6.70, Rs 8.14, Rs 6.02 and Rs 11.91 respectively having $10 \mathrm{~g}$ of healthy heart mixture.

\section{Conclusion}

On the basis of the present study it can be concluded that the healthy heart mixture which is rich in dietary fiber possess a great potential in lowering LDL cholesterol level and thus in effective management of cardiovascular disease. It can be incorporated in various recipes at household level. In this study it has been incorporated in Khakhra, Thepla, Baked Mathri and Baked Namkeen with a positive acceptability of product with code 552, 662, 772 and 882 having $10 \%$ of healthy heart mixture and the variations developed by incorporating $20 \%$ of healthy heart mixture was also found to be acceptable. The cost per $100 \mathrm{~g}$ of healthy heart mixture was Rs 44 which is easily affordable by a common man. The cost calculated for the most acceptable recipe was Rs 6.70 (Khakhra), Rs 8.14 (thepla), Rs 6.02 (baked mathri) and Rs 11.91 (baked namkeen). The prepared recipes can be consumed by the patient at any time of the day either with breakfast or with evening tea. Thepla can be consumed along with milk/tea/juice and recipes like khakhra, baked mathri and baked namkeen can be munched at any time of the day. Thus this healthy heart mixture can be consumed regularly and can also be incorporated in other recipes like chappati, cheela, uttapam, idli etc for the effective management of cardiovascular disease.

\section{References}

[1] Adolphe, J., 2015. Flaxseed and Cardiovascular Disease. $\quad$ Retrieved from www.healthyflax.org/quadrant/media/files/pdf/HEAL.fa ctsheet_CARDIO.pdf

[2] Arranz, S., Remon, A., Raventos, R., and Estruch, R., 2012. Effects of Dietary Fiber Intake on Cardiovascular Risk Factors. Retrieved from http://www.intechopen.com/books/howtoreference/rece nt-advances-in-cardiovascular-risk-factors/effects-ofdietary-fiber-inatke-on-cardiovascular-risk-factors

[3] Arranz, S., Remon, A., Raventos, R., and Estruch, R. 2012. Effect of dietary fiber intake on cardiovascular risk factors. 460-480.

[4] Bernacchia, R., Preti, R., Vinci, G. 2014. Chemical composition and health benefits of flaxseed. Austin Journal of Nutrition and Food Sciences.

[5] Brown, L., Rosner, B., Willett, W. W., and Sacks, M. F. 2016. Cholesterol-lowering effects of dietary fiber: a meta-analysis. The American Journal of Clinical Nutrition, 69:30-42.

[6] Coleman, E., 2013. Dietary Fiber and Cholesterol Reduction. Retrieved from www.nutrition411.com/pdf/Dietary\%20Fiber\%20and\% 20cholestrol\%20Reduction.pdf

[7] Goyal, A., Sharma, V., Upadhyay, N., Gill, S., and Sihag, M. 2014. Flax and Flaxseed oil: an ancient medicine and modern functional food. $\mathrm{J}$ Food Sci Technol, 51(9):1633-1653.

[8] Katz, L., 2001. A Scientific Review of the Health Benefits of Oats. Yale University School of Medicine.

[9] Narayan, R., 2005. Meet psyllium: A Fiber Product with Potential Cardioprotective Effects. Nutrition Noteworthy, 7(1), 1-6. Retrieved from http://escholarship.org/uc/item/6pr0g8dj.

[10] Rathi, P., Mogra, R. 2012. Development and sensory evaluation of superior products with flaxseed. International journal of food and nutritional sciences. ISSN 2320-7876.

\section{Volume 5 Issue 6, June 2016 www.ijsr.net}




\section{International Journal of Science and Research (IJSR) \\ ISSN (Online): 2319-7064}

Index Copernicus Value (2013): 6.14 | Impact Factor (2015): 6.391

[11] Shah, B., Mathur, P. 2010. Surveillance of cardiovascular disease risk factors in India: The need and scope. Indian journal of medical research. Pp. 634642.

[12] World Health Organization. 2013. Retrieved from http://googleweblight.com/?lite_url=http://www.who.int /cardiovascular_diseases/en/\&ei=IPx606E9\&lc=en-

$\mathrm{IN} \& \mathrm{~s}=1 \& \mathrm{~m}=615 \& \mathrm{ts}=1440132104 \& \mathrm{sig}=\mathrm{APONPFmkL}$

Omq5ym4ZIF01I8tAj1_ntV5MQ

Volume 5 Issue 6, June 2016 www.ijsr.net

Licensed Under Creative Commons Attribution CC BY 